\title{
Post-mortem surveillance of bovine tuberculosis in Ireland: herd-level variation in the probability of herds disclosed with lesions at routine slaughter to have skin test reactors at follow-up test
}

\author{
Andrew W. Byrne ${ }^{1}$ (D) $\cdot$ Damien Barrett ${ }^{1} \cdot$ Philip Breslin $^{2} \cdot$ Jamie M. Madden $^{3} \cdot$ James O'Keeffe $^{2} \cdot$ Eoin Ryan $^{2}$
}

Received: 19 May 2020 / Accepted: 17 June 2020 / Published online: 24 June 2020

(C) Springer Nature B.V. 2020

\begin{abstract}
Post-mortem surveillance in Ireland discloses skin-test negative cattle with presumptive evidence of infection of Mycobacterium bovis (lesions at routine slaughter (LRS)), the causative agent of bovine tuberculosis (bTB). Laboratory confirmation of lesions has impacts on trade restrictions for herds, therefore if laboratory capacity was diminished, how herds are treated would require an informed risk policy. Here we report the proportion of herds with subsequent evidence of within-herd transmission, based on skin-test results. We assess how herd-size, herd-type, and bTB-history affect the probability of additional reactors at follow-up test using univariable and multivariable random-effects models. The study represents a rapid response to developing an evidential base for policy demands during an extraordinary event, the COVID-19 epidemic in Ireland. A dataset from 2005 to 2019 of breakdowns were collated. Overall, 20,116 breakdowns were initiated by LRS cases. During the index tests of these breakdowns, 3931 revealed $\geq 1$ skin-test reactor animals $(19.54 \% ; \geq 1$ standard reactors: $3827 ; 19.02 \%)$. Increasing herd-size was associated with reactor disclosure on follow-up. For small herds ( $<33$ animals), $11.74 \%$ of follow-up tests disclosed $\geq 1$ reactor; $24.63 \%$ of follow-up tests from very large herds ( $>137)$ disclosed $\geq 1$ reactors. Beef (13.87\%) and "other" (13\%) herd production types had lower proportion of index tests with reactors in comparison with dairy $(28.27 \%)$ or suckler $(20.48 \%)$ herds. Historic breakdown size during the previous 3-years was associated reactor disclosure risk on follow-up. Our results are useful for rapid tailored policy development aimed at identifying higher risk herds.
\end{abstract}

Keywords Bovine tuberculosis $\cdot$ Evidence-based policy $\cdot$ Disease control $\cdot$ Veterinary epidemiology

\section{Introduction}

Post-mortem (PM) confirmation of infection of Mycobacterium bovis has been extensively studied in cattle herds, including the

Electronic supplementary material The online version of this article (https://doi.org/10.1007/s11259-020-09777-w) contains supplementary material, which is available to authorized users.

Andrew W. Byrne

andreww.byrne@agriculture.gov.ie

1 One-Health Scientific Support Unit, SAT Division, Department of Agriculture, Food and the Marine, Agriculture House, Dublin 2 , Ireland

2 Ruminant Animal Health Division, Department of Agriculture, Food and the Marine, Backweston, Co. Dublin, Ireland

3 Centre for Veterinary Epidemiology and Risk Analysis (CVERA), School of Veterinary Medicine, University College Dublin, Belfield, Dublin 4, Ireland presence of pathology (visible lesions) and the culturing of the pathogen (Byrne et al. 2017; Milne et al. 2019; Shittu et al. 2013; Murray et al. 2012), as part of bovine tuberculosis control programs. Such post-mortem data are important for confirming the quality of the antemortem testing occurring during large scale control programs (Olea-Popelka et al. 2012; Frankena et al. 2007; Lahuerta-Marin et al. 2016). Furthermore, slaughterhouse surveillance data at a population level gives a good independent indicator of underlying trends infection over time, especially during times of changes in the application, use or type of antemortem tests being employed (Abernethy et al. 2013; More et al. 2018). The presence of lesions has been used as an additional metric of infection to estimate the performance of antemortem TB tests used to disclose infected cattle (Courcoul et al. 2014; McCallan et al. 2017; Karolemeas et al. 2012; Lahuerta-Marin et al. 2018). Possibly most importantly, PM surveillance discloses cases that may have been otherwise missed via antemortem testing programs (Humphrey et al. 2014; Garcia-Saenz et al. 2015; Lahuerta- 
Marin et al. 2016; Pascual-Linaza et al. 2017; Willeberg et al. 2018). Animals with confirmed lesions found at routine slaughter (LRS, also known as 'factory lesion cases') can result in herd restrictions (disease 'breakdowns'), which have significant impact on farmers. Once a lesion is found, the herd's trading status is immediately 'suspended'. If lesions are confirmed via laboratory means (histology, culture), herds trading status move to 'withdrawn', and normal trading cannot be returned until two clear tests are achieved (Good et al. 2017).

There has been limited work to assess the variation in the follow-up testing following the disclosure of a lesion in an ante-mortem test negative animal, and the variation in follow-up disclosure of skin test positive animals (but see Olea-Popelka et al. 2008). It is important, from an epidemiological, policy, and disease control program perspective, to understand how follow-up disclosure of infection might vary across different herd enterprise types or sizes, and how policy changes could be tailored to differing contexts or events.

Here we use a dataset on herd breakdowns in Ireland from 2005 to 2019 to explore the variation in, and risk to, follow-up skin test reactor disclosure after a herd breakdown was initiated due to the finding of a lesion at slaughter. This paper was developed from a need for a rapid response to a changing resource laboratory capacity in Ireland during an extraordinary event - the pandemic of COVID-19. The requirement for laboratory capacity for testing for SARS-CoV2 virus (causative agent of COVID-19) had an acute impact on M. bovis confirmation rates. This reduced capacity had a direct effect on the policy for restrictions/de-restrictions and therefore an interim policy was required based on risk profile at herd-level. Our work highlights how timely epidemiological data analytics capacity at the heart of government policy making can help inform decision making during extraordinary events.

\section{Methods}

Data were collated from the Animal Health Computer System (AHCS) and restructured such that each line within our dataset represented a discrete breakdown (BD) event. The initiation test and the whether a herd entered a breakdown due to the presence of a lesion detected at routine slaughter (LRS), were derived for each BD. Only herds which were flagged as initiated as a factory slaughter case (LRS) was retained, which was denoted within our dataset as "Slaughter (non-permit animal)". Antemortem testing data was primarily 'reactor' animals, which included all animals removed as part of an official test, including standard reactors, "inconclusive" reactors, and interferon gamma test positive animals. We also report descriptive statistics for standard reactors. We modelled all reactors here in an attempt to: 1. Improve the relative animal- level sensitivity of the antemortem testing regime 2 . To understand better the patterns as measured in the field within the Irish program.

We derived the herd size, based on the testing history of the herd within the dataset (see supplementary material). Herd size was modelled as a continuous [ $\log _{\mathrm{n}}$ transformed] and as a categorical variable (small: $\leq 32$; medium: $33-71$; large: 72 136; very large: 137-3095). Herd type was derived from the AHCS flag, and had four categories - beef, dairy, suckler or other herd types.

\section{Statistical analysis}

The outcome was a binary response (reactors disclosed, yes/ no), and was modelled using a logit distribution. Temporal trend analysis was undertaken by modelling time as both a continuous linear predictor, and as a categorical variable for each year of the study, in separate logistic models.

As there were multiple observations per herds (Obs per group: $\min =1 ;$ avg. $=1.7 ; \max =13)$, random effects $(\mathrm{RE})$ models were fitted to the data (herd identifier $=\mathrm{RE}$ ). Univariable models were fitted, to assess unadjusted associations between dependent and independent variables. A fully saturated multivariable model was fitted to the data (i.e. all herd and temporal factors fitted as explanatory variables), and compared to simpler models where covariates were removed, using Akaike's information criterion (AIC). The model with the lowest AIC was presented.

\section{Results}

A dataset from 2005 to 2019 of breakdowns were collated. Overall, 20,116 breakdowns were initiated by "Slaughter (non-permit animal)" cases. During the index tests of these breakdowns, 3931 revealed $>1$ reactor animals $(19.54 \%$; $>1$ standard reactors: $3827 ; 19.02 \%$ ). There was a significant decline in the probability of herds disclosing reactors on follow-up over time (Fig. 1). A univariable logistic trend model, using year as a single continuous predictor, suggested a significant decline of OR 0.958 per year $(P<0.001$; 95\%CI: $0.950-0.967)$.

\section{Herd size}

Herd size was associated with reactor disclosure on follow-up index tests. The relationship was curvilinear, with herd-size modelled as a $\log _{\mathrm{n}}$ transform (unadjusted OR: 1.456 ; 95\%CI: 1.395-1.521; Fig. S1). For small herds ( $<33$ animals), $11.74 \%$ of index tests disclosed $>1$ reactors; $24.63 \%$ of index tests from very large herds $(>137)$ disclosed $>1$ reactors (Table 1). The univariable RE logit model results are presented in Table S1. 


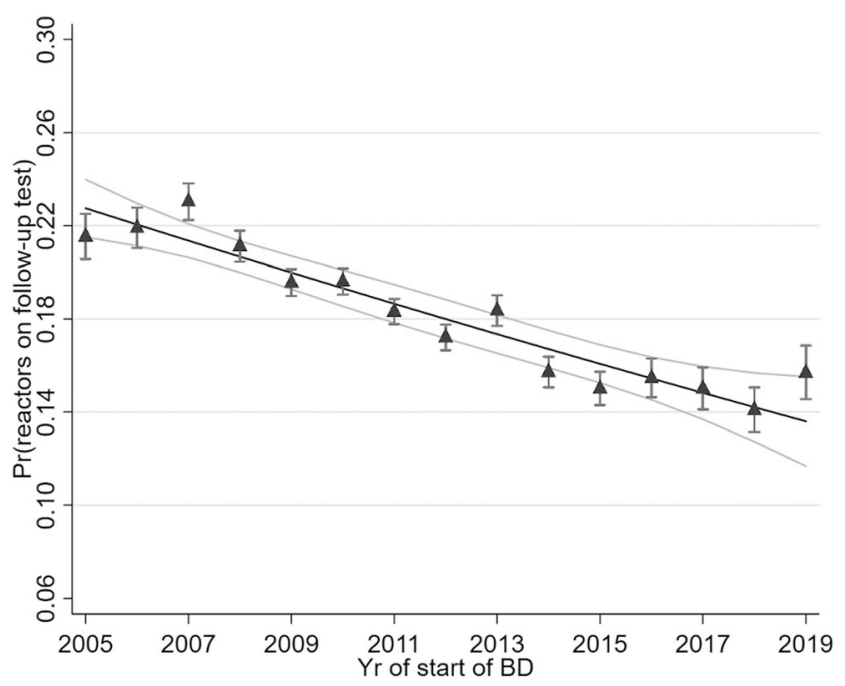

Fig. 1 Relationship between reactor disclosure risk on follow-up and year. Point estimates are from a logistic model with one predictor, year, modelled as a categorical variable. Trend line is from a linear model using year as a continuous variable. Error bars $=95 \% \mathrm{CI}$

\section{Herd type}

There was significant variation in the proportion of index tests disclosed reactors amongst herd types (univariable RE logit model; Table 2, S2). Beef (13.87\%) and "other" (13\%) herd production types had lower proportion of index test with reactors in comparison with dairy $(28.27 \%)$ or suckler $(20.48 \%)$ herds. Dairy (OR: 2.7) and suckler (OR: 1.7) had significantly higher risk than beef of disclosing reactors on follow-up. 'Other' had significantly lower risk, relative to beef (OR: $0.9)$. Dairy had significantly higher risk than suckler herds (post-hoc Wald test: $\chi^{2}$ (DF: 1$)=79.47$; Prob $>\chi^{2}<0.001$ ).

\section{History}

Overall, there were $14,110(70.14 \%)$ observations within the dataset that had $>3$-year histories, that was not truncated by being recorded early in the dataset (number of herds: 10,875). Overall, $34.69 \%$ of these observations $(4934 / 14,110)$ were

Table 1 Relationship between herd size, spit into categories, and whether LRS herds disclosed reactors on follow-up test

\begin{tabular}{llllll}
\hline LRS-index result & Small & Medium & Large & Very Large & Total \\
\hline Reactors & & & & & \\
No & 3768 & 3904 & 3993 & 4520 & 16,185 \\
$(\%)$ & 88.26 & 82.85 & 77.72 & 75.37 & 80.46 \\
Yes & 501 & 808 & 1145 & 1477 & 3931 \\
$(\%)$ & 11.74 & 17.15 & 22.28 & 24.63 & 19.54 \\
Total & 4269 & 4712 & 5138 & 5997 & 20,116 \\
& 100 & 100 & 100 & 100 & 100 \\
\hline
\end{tabular}

Table 2 Relationship between herd type and whether LRS herds disclosed reactors on follow-up test

\begin{tabular}{llllll}
\hline LRS-index result & Beef & Diary & Other & Suckler & Total \\
\hline Reactors & & & & & \\
No & 5147 & 2773 & 1111 & 7154 & 16,185 \\
$(\%)$ & 86.13 & 71.73 & 87 & 79.52 & 80.46 \\
Yes & 829 & 1093 & 166 & 1843 & 3931 \\
$(\%)$ & 13.87 & 28.27 & 13 & 20.48 & 19.54 \\
Total & 5976 & 3866 & 1277 & 8997 & 20,116 \\
& 100 & 100 & 100 & 100 & 100 \\
\hline
\end{tabular}

associated with breakdown during the preceding 3 years. $32.09 \%$ of herds experienced a breakdown during the preceding 3 years $(3490 / 10,875)$.

Of the historic breakdowns, $42.52 \%$ (2098/4934) were initiated by the disclosure of $\geq 1$ reactor during an index test. Of these, 33.13\% (695/2098) were single reactor breakdowns.

Table 3 shows the breakdown of herd history types and the respective proportion disclosing with skin test reactors on LRS follow-up. $18.12 \%$ of herds without a breakdown within 3 years had reactors on LRS follow-up; whereas $30.70 \%$ of herds which had a BD of 5+ reactors disclosed reactors on LRS follow-up.

There was a significant increase risk of a herd disclosing reactors, if they experienced a breakdown during the previous 3 -year window (univariable logit model: $\chi^{2}$ (DF: 4$)=86.16$; Prob $\left.>\chi^{2}<0.001\right)$. This was primarily driven by larger previous BDs (Table S3). There was no significant difference in the disclosure of reactors during a follow-up test, between herds without previous breakdown (within 3 years) and those that disclosed single reactor breakdowns (no previous BD vs. single reactor BD: OR: 1.14; 95\%CI: $0.93-1.40 ; p=0.212$ ).

Of the herds which had a breakdown during the previous 3 years $(N=4933)$, there was no relationship between the time since last breakdown and skin test reactor disclosure risk on LRS follow-up test (unadjusted OR: 1.00; $P=0.723$ ).

Table 3 Proportion of herds which disclose reactors after an LRS breakdown by herd TB history

\begin{tabular}{llllll}
\hline $\begin{array}{l}\text { LRS-index } \\
\text { result }\end{array}$ & $\begin{array}{l}\text { No prev. } \\
\text { BD }\end{array}$ & $\begin{array}{l}\text { Zero- } \\
\text { reactor } \\
\text { BD }\end{array}$ & $\begin{array}{l}\text { Single } \\
\text { reactor } \\
\text { BD }\end{array}$ & $\begin{array}{l}2-4 \\
\text { reactor } \\
\text { BD }\end{array}$ & $\begin{array}{l}5+ \\
\text { reactor } \\
\text { BD }\end{array}$ \\
\hline Reactors & & & & & \\
No & 7514 & 2455 & 550 & 566 & 456 \\
$(\%)$ & 81.88 & 86.60 & 79.14 & 75.97 & 69.30 \\
Yes & 1663 & 380 & 145 & 179 & 202 \\
$(\%)$ & 18.12 & 13.40 & 20.86 & 24.03 & 30.70 \\
Total & 9177 & 2835 & 695 & 745 & 658 \\
\hline
\end{tabular}




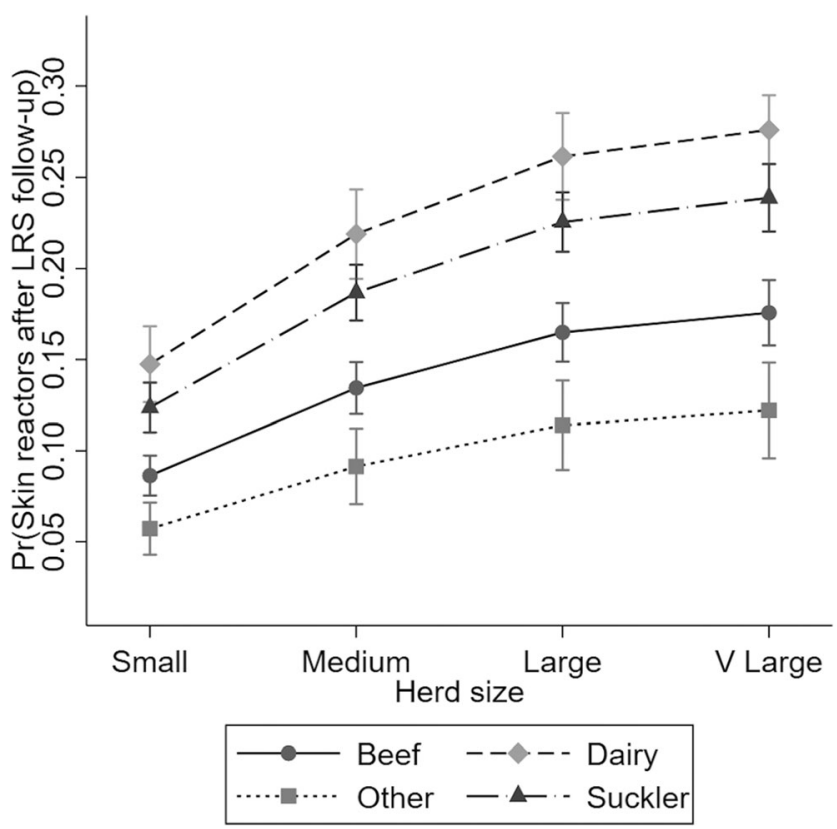

Fig. 2 Variation of marginal risk of additional disclosure of skin test positive animals after lesions found at routine slaughter in relation to herd size and herd enterprise type

\section{Multivariable model}

The final multivariable model is presented in Table 4. All variables presented to the model were retained as they explained some variation in the outcome, and more parsimonious models had greater AIC values. Beef (aOR: 0.56), Suckler
(aOR: 0.83) and 'other' (aOR: 0.35) herds were significantly lower risk of disclosing reactors at follow-up, relative to dairy herds. Risk of disclosing reactors at follow-up increased with increasing herd size (Fig. 2), for example, very large herds (>137 cattle) were 2.38 (95\%CI: 2.01-2.80) times the odds of reactor disclosure relative to small herds ( $\leq 32$ cattle). Controlling for confounders, over time there was a decreasing trend in the risk of disclosing reactors (aOR: 0.96 ; 95\% CI: 0.94-0.97). There was increasing risk associated with the number of reactors disclosed during herd's previous breakdown. For example, having a large breakdown (5+ reactors) during the previous 3 years was associated with increased risk of disclosing reactors at LRS follow-up (relative to zeroreactor breakdowns: aOR: 2.10 ; 95\% CI: 1.68-2.62). Controlling for confounders, our model suggested that herds that did not experience a breakdown within the last 3-years were at higher risk (aOR: 1.42 ; 95\%CI: $1.24-1.63$ ) relative to herds which had a previous zero-reactor breakdowns (i.e. LRS initiated breakdowns without additional reactors disclosed at follow-up).

\section{Discussion}

Bovine tuberculosis remains a priority statutory disease in cattle herds in Ireland which requires rapid evaluation of data to inform policy decisions (More 2019). The present study demonstrated that there were characteristics of herds
Table 4 Multivariable logit random effects model of factors associated with herds disclosing reactors after disclosure of lesion at routine slaughter (LRS)

\begin{tabular}{lllllll}
\hline LRS-index result & Odds Ratio & Std. Err. & $\mathrm{z}$ & $\mathrm{P}>\mathrm{z}$ & L95\% & U95\% \\
\hline Herd type & & & & & & \\
Dairy & 1.000 & referent & & & & \\
Beef & 0.559 & 0.044 & -7.470 & 0.000 & 0.479 & 0.651 \\
Other & 0.352 & 0.049 & -7.540 & 0.000 & 0.268 & 0.462 \\
Suckler & 0.830 & 0.056 & -2.790 & 0.005 & 0.727 & 0.946 \\
Herd size & & & & & & \\
Small & 1.000 & referent & & & & \\
Medium & 1.679 & 0.136 & 6.410 & 0.000 & 1.433 & 1.968 \\
Large & 2.179 & 0.174 & 9.770 & 0.000 & 1.864 & 2.548 \\
Very large & 2.374 & 0.199 & 10.320 & 0.000 & 2.014 & 2.797 \\
Herd history & & & & & & \\
No prev. BD & 1.424 & 0.099 & 5.100 & 0.000 & 1.243 & 1.631 \\
Zero-reactor BD & 1.000 & referent & & & & \\
Single reactor BD & 1.518 & 0.183 & 3.450 & 0.001 & 1.198 & 1.923 \\
2-4 reactor BD & 1.665 & 0.191 & 4.440 & 0.000 & 1.330 & 2.085 \\
5+ reactor BD & 2.103 & 0.239 & 6.540 & 0.000 & 1.683 & 2.627 \\
Time (unit: year) & & & & & & \\
BD start year & 0.956 & 0.007 & -6.160 & 0.000 & 0.943 & 0.970 \\
Constant & 0.206 & 0.023 & -14.290 & 0.000 & 0.165 & 0.255 \\
\hline
\end{tabular}


associated with additional reactors being disclosed after an ante-mortem negative animal was found to have postmortem evidence of $M$. bovis infection at post-mortem surveillance. These characteristics, herd size, herd type and bTB history, are readily available within national databases allowing for refinement of follow-up policy and resource attribution in near real time. The risk of disclosure of additional ante-mortem test positive animals was increased in larger herds, in dairy and suckler herds relative to beef or other herds, and herds with a history of infection. These three variables have been identified as important risk factors for bTB generally at a herd-level (Allen et al. 2018; Skuce et al. 2008), but have also been reported to be associated with increased recurrence risk (e.g. Wolfe et al. 2010; Karolemeas et al. 2011) and prolonged breakdown length (Milne et al. 2020; Doyle et al. 2016). Recurrence in herds may be related to environmental exposure or buying in (trade) behaviour and biosecurity practices (Palisson et al. 2016; Milne et al. 2019). It may also suggest that the clearance of infection from previous breakdowns might not be robust. Olea-Popelka et al. (2008) studied herds attested clear which disclosed reactors after the discovery of a factory lesion in Ireland 12-years prior to the current study. The percentage of herds disclosing a standard reactor across that study was $19.7 \%$, while the present study suggested $19.0 \%$ of herd disclosed $\geq 1$ standard reactors. Furthermore, there was evidence in the present study that this percentage declined from 2013 to 2018; as Fig. 1 demonstrates, the proportion declined from approximately $\sim 22 \%$ to $\sim 14 \%$. The present study confirmed a previous finding that beef herds are significantly lower risk of disclosing additional reactors post-LRS relative to dairy and suckler herds (OleaPopelka et al. 2008). Dairy herds were significantly higher risk than either suckler or beef herds. Herd-size could be related to the intensity of agriculture being undertaken within farm, and may correlate on inward movement of animals, depending on enterprise type (Olea-Popelka et al. 2008; Skuce et al. 2012). Herd history over the previous 3-years was important when previous breakdowns were large in the present study ( $>5$ reactors). Olea-Popelka et al. (2008) found that the number of years a herd tested negative was not associated with reactor disclosure after LRS, when the lesioned animal was not present in the herd at last breakdown. Interestingly, our present study found that herds which experienced a breakdown caused by LRS (zero-reactor breakdowns) within 3-years were lower risk than herds who remained TB "clear" during the previous 3-years. This may suggest that some herds could have greater risk of repeating LRS breakdowns. LRS presence has been found to be a risk factor for breakdown recurrence (Doyle et al. 2017), though we are not aware of data that suggests that repeated LRS breakdowns could cluster within herds. At an animal level, LRS presence has been associated with older cattle, those that have moved between herds, and have been residing in herds which had recent breakdowns (e.g. $<3$ yrs) (Lahuerta-Marin et al. 2016; Clegg et al. 2016). At a herd level, LRS disclosure have been associated with higher risk herds, which can experience long duration breakdowns, that buy in animals, and are situated in high risk geographic regions (Shittu et al. 2013; Milne et al. 2020).

A limitation of this study was that animal level data and animal movements (introductions) were not used to model our outcome, which limits the amount of variation explained by our model. However, this was deemed acceptable, as the primary purpose of the model was to inform on follow-up risk from a limited number of herd-level characteristics that could be informative to policy makers during a period of unprecedented challenge - the COVID-19 outbreak in Ireland (Griffin et al. 2020).

The present study was undertaken in response to a rapidly changing policy environment, where capacity to undertake post-mortem confirmation surveillance was impacted by a major event, the COVID-19 pandemic, which negatively affected laboratory capacity. The study demonstrated that a rapid response via epidemiological assessment of key parameters could inform on emergency policy response.

Authors contributions PB, ER conceived the study. AWB, PB, ER designed the study; JM constructed breakdown-level dataset; AWB undertook statistical analyses with input from JM; AWB drafted the paper with contributions from all other authors. All authors read and approved the final manuscript.

Funding information No specific funding is associated with this work.

Data availability The datasets analysed during the current study are available from Department of Agriculture, Food and the Marine, but will be subject to all data protection regulations and limitations (https://www. agriculture.gov.ie/dataprotection/).

\section{Compliance with ethical standards}

Conflict of interest The authors declare no conflict of interest.

\section{References}

Abernethy DA, Upton P, Higgins IM, McGrath G, Goodchild AV, Rolfe SJ, Broughan JM, Downs SH, Clifton-Hadley R, Menzies FD, De la Rua-Domenech R (2013) Bovine tuberculosis trends in the UK and the Republic of Ireland 1995-2010 Vet Rec https://doi.org/10.1136/ vr.100969

Allen AR, Skuce RA, Byrne AW (2018) Bovine tuberculosis in Britain and Ireland-A perfect storm? the confluence of potential ecological and epidemiological impediments to controlling a chronic infectious disease. Front Vet Sci 5:109. https://doi.org/10.3389/fvets.2018. 00109

Byrne AW, Graham J, Brown C, Donaghy A, Guelbenzu-Gonzalo M, McNair J, Skuce R, Allen A, McDowell S (2017) Bovine tuberculosis visible lesions in cattle culled during herd breakdowns: the effects of individual characteristics trade movement and co- 
infection. BMC Vet Res 13:400. https://doi.org/10.1186/s12917017-1321-z

Clegg TA, Good M, More SJ (2016) Risk factors for cattle presenting with a confirmed bTB lesion at slaughter from herds with no evidence of within-herd transmission. Prev Vet Med 126:111-120

Courcoul A, Moyen JL, Brugere L, Faye S, Henault S, Gares H, Boschiroli ML (2014) Estimation of sensitivity specificity of bacteriology histopathology and PCR for the confirmatory diagnosis of bovine tuberculosis using latent class analysis. PLoS One 9:3

Doyle LP, Courcier EA, Gordon AW, O'Hagan MJH, Menzies FD (2016) Bovine tuberculosis in Northern Ireland: Risk factors associated with duration and recurrence of chronic herd breakdowns. Preventive Veterinary Medicine 131:1-7

Frankena K, White PW, O'Keeffe J, Costello E, Martin SW, Van Grevenhof I, More SJ (2007) Quantification of the relative efficiency of factory surveillance in the disclosure of tuberculosis lesions in attested Irish cattle Vet Rec 161:679-684

Garcia-Saenz A, Napp S, Lopez S, Casal J, Allepuz A (2015) Estimation of the individual slaughterhouse surveillance sensitivity for bovine tuberculosis in Catalonia (north-eastern Spain). Prev Vet Med 121(3-4):332-337

Good M, Duignan A, Maher P, O'Keeffe J (2017) Veterinary handbook for herd management in the bovine TB eradication programme Department of Agriculture Food and the marine Dublin Ireland

Griffin JM, Collins AB, Hunt K, McEvoy D, Casey M, Byrne AW, McAloon CG, Barber A, Lane EA, More SJ (2020) A rapid review of available evidence on the serial interval and generation time of COVID-19 medRxiv. https://doi.org/10.1101/2020.05.08. 20095075

Humphrey HM, Orloski KA, Olea-Popelka FJ (2014) Bovine tuberculosis slaughter surveillance in the United States 2001-2010: assessment of its traceback investigation function. BMC Vet Res 10:182

Karolemeas K, de la Rua-Domenech R, Cooper R, Goodchild AV, Clifton-Hadley RS, Conlan AJ, Mitchell AP, Hewinson RG, Donnelly CA, Wood JL, McKinley TJ (2012) Estimation of the relative sensitivity of the comparative tuberculin skin test in tuberculous cattle herds subjected to depopulation. PLoS One 2012;7(8)

Karolemeas K, McKinley TJ, Clifton-Hadley RS, Goodchild AV, Mitchell A, Johnston WT, Conlan AJK, Donnelly CA, JLN W (2011) Recurrence of bovine tuberculosis breakdowns in Great Britain: risk factors and prediction. Prev Vet Med 102:22-29

Lahuerta-Marin A, McNair J, Skuce R, McBride S, Allen M, Strain SA, Menzies FD, McDowell SJ, Byrne AW (2016) Risk factors for failure to detect bovine tuberculosis in cattle from infected herds across Northern Ireland (2004-2010). Res Vet Sci 107:233-239. https://doi.org/10.1016/j.rvsc.2016.06.014

Lahuerta-Marin A, Milne MG, McNair J, Skuce RA, McBride SH, Menzies FD, McDowell SJW, Byrne AW, Handel IG, BDC B (2018) Bayesian latent class estimation of sensitivity and specificity parameters of diagnostic tests for bovine tuberculosis in chronically infected herds in Northern. Ireland Vet J 238:15-21. https://doi.org/ 10.1016/j.tvj1.2018.04.019

McCallan L, Brooks C, Couzens C, Young F, McNair J, Byrne AW (2017) Assessment of serological tests for diagnosis of bovine tuberculosis Vet Rec ppvetrec-2016 https://doi.org/10.1136/vr. 104272
Milne G, Allen A, Graham J, Lahuerta-Marin A, McCormick C, Presho E, Reid N, Skuce R, Byrne AW (2020) Bovine tuberculosis breakdown duration in cattle herds: an investigation of herd host pathogen and wildlife risk factors PeerJ 8 pe8319 https://doi.org/10.7717/ peerj. 8319

Milne MG, Graham J, Allen A, McCormick C, Presho E, Skuce R, Byrne AW (2019) Variation in Mycobacterium bovis genetic richness suggests that inwards cattle movements are a more important source of infection in beef herds than in dairy herds. BMC Microbiol 19:154. https://doi.org/10.1186/s12866-019-1530-7

More SJ (2019) Can bovine TB be eradicated from the Republic of Ireland? Could this be achieved by 2030 ? Irish veterinary journal 72(1):1-10

More SJ, Houtsma E, Doyle L, McGrath G, Clegg TA, de la RuaDomenech R, Duignan A, Blissitt MJ, Dunlop M, Schroeder PG, Pike R (2018) Further description of bovine tuberculosis trends in the United Kingdom and the Republic of Ireland 2003-2015. Vet Rec 183:717

Murray D, Clegg TA, More SJ 2012 Evaluation of single reactor bovine tuberculosis breakdowns based on analysis of reactors slaughtered at an Irish export meat plant. Vet Rec

Olea-Popelka FJ, Costello E, White P, McGrath G, Collins JD, O'Keeffe J, Kelton DF, Berke O, More S, Martin SW (2008) Risk factors for disclosure of additional tuberculous cattle in attested-clear herds that had one animal with a confirmed lesion of tuberculosis at slaughter during 2003 in Ireland. Prev Vet Med 85:81-91

Olea-Popelka F, Freeman Z, White P, Costello E, O'Keeffe J, Frankena K, Martin W, More S (2012) Relative effectiveness of Irish factories in the surveillance of slaughtered cattle for visible lesions of tuberculosis, 2005-2007. Irish Veterinary Journal 65(1):2

Palisson A, Courcoul A, Durand B (2016) Role of cattle movements in bovine tuberculosis spread in France between 2005 and 2014. PLoS One 11(3)

Pascual-Linaza AV, Gordon AW, Stringer LA, Menzies FD (2017) Efficiency of slaughterhouse surveillance for the detection of bovine tuberculosis in cattle in. Northern Ireland Epidemiol Infect 145(5): 995-1005

Shittu A, Clifton-Hadley RS, Ely ER, Upton PU, Downs SH (2013) Factors associated with bovine tuberculosis confirmation rates in suspect lesions found in cattle at routine slaughter in. Great Britain 2003-2008 Prev Vet Med 110(3-4):395-404

Skuce RA, Allen AR, McDowell SW (2012) Herd-level risk factors for bovine tuberculosis: a literature review Vet Med Intern 2012 doi: https://doi.org/10.1155/2012/621210

Willeberg PW, McAloon CG, Houtsma E, Higgins I, Clegg TA, More SJ (2018) The herd-level sensitivity of abattoir surveillance for bovine tuberculosis: Simulating the effects of current and potentially modified meat inspection procedures in Irish cattle. Front Vet Sci 5:82

Wolfe DM, Berke O, Kelton DF, White PW, More SJ, O'Keeffe J, Martin SW (2010) From explanation to prediction: a model for recurrent bovine tuberculosis in Irish cattle herds Prev Vet Med 94:70-177

Publisher's Note Springer Nature remains neutral with regard to jurisdictional claims in published maps and institutional affiliations. 